\title{
Research on the Synergy Management Mechanism of the Project Contract Using Management Based on the Multi-sided Matching Decision Method Gang $\mathrm{Du}^{1}$, Ping $\mathrm{Du}^{2}$
}

\author{
${ }^{1}$ Audit Department, China telecom corporation limited beijing branch, Beijing, 100000, China \\ ${ }^{2}$ Economic and Management Department,North of China Electric Power University,Baoding, \\ 071000, China
}

Keywords: Synergy Management; Project Contract; Mutual Benefit ; Multi-sided Matching

\begin{abstract}
Synergy management in project aims to maximizing the all parties' interests the owner, which parties including the construction unit, contractors, suppliers, government. It is the management core, in order to maximize their interests we try to carry out the new management mode of the integration. Synergy management, both the contemporary management due to the inherent law of development, is also better implementation projects benefit maximization by request of reality. Therefore, the synergy model and the multi-sided matching decision method used in project management research are important theoretical significance and practical value. The paper puts forward the theoretical support of synergy management, and uses the basic idea of constructing public opinion model and the multi-sided decision method to analyze the trends of subject selection decision. Then, the feasibility of synergy management mechanism is confirmed, and finally build synergy mechanism theory model.
\end{abstract}

\section{Introduction}

With the further development of the global economy, science and technology level, and the social division of labor becoming more and more subtle, the size of separate project is gradually increased, and a single project scope is expanding. Stakeholders involved in growing, it is necessary to consider expanding the scope of the whole life cycle concept deepening. As well to reconcile the interests of all parties, to achieve the overall benefit maximization and the whole life cycle of benefit maximization, synergy management mechanism arises at the historic moment.

Under the new situation, the use of synergy management mechanism can not only do current development trend of project management, but also can utilize the comprehensive effect of various parties, improvement and innovation management mechanism. The establishment of the project management synergy mechanism is facing the demand in the field of project management. It, guided by the synergy management concept, aims to building the synergy management platform. Then we can promote the partners who are the owner, the construction unit, contractors, suppliers, government, such as the depth of cooperation, to establish good relations of cooperation, strategic alliance, and even improve the interests of all parties, in practice, substantive results.

This paper is divided into different sections. Section 2 surveys theoretical support of synergy management mechanism. Synergy mechanism mode and the multi-sided matching method are illustrated in Section 3. Section 4 we Build the synergy mechanism of project contract management. Lastly, conclusions are described in Section5.

\section{Theoretical support of synergy management mechanism}

Any development level of productivity will cause the further development of division of labor cooperation. The division of labor is a crystallization of social production and is also an important symbol of socialization labor. Adam Smith said the biggest reason to increase labor productivity and use of labor more adept, skills and judgment is the division of labor. Division of labor has greatly promotes the productivity and the progress of the society. 


\subsection{The basement of the synergy}

At the same time, Marshall pays attentions to the positive role of increasing returns about great importance to the organization. Or in other words, it is the role of social division of labor. This from the side confirmed that the division of labor and organization are linked together. Kuhn - tucker theorem can solve the problem of division of labor organization structure, Williamson et al. study enriched the theory of division of labor cooperation activities.

Social division of labor is the result of the development of social productive forces. Social division of labor is the result of the development of social productivity. Division of labor makes the social from all walks of life to become vitality. Social division of labor has skilled in the technology, perfect in the work. But, as the project scale and scope expanding gradually, and the social division of labor and transaction cost has increased dramatically, it maybe contains lemon market possibilities because of the information asymmetry. In the middle of the division of labor cooperation we set up a bridge to ensure that the benefits brought by social division of labor. And at the same time, it is as far as possible to reduce the negative effects of social division of labor. The point has become one of key in the field of management, project management also.

Based on building model, the individual participants of the whole project as defined within the enterprise in all sorts of assets, is the scope of the enterprise intangible enlargement, the purpose is to make to participate in the project contract signed by the parties to the overall effectiveness of implementation, the largest of economics will be used to allocate do big cake, distributor to get the copy of the nature also as bigger. Known from the analysis of the above, the comprehensive management on the project, the whole life cycle and balance the interests of all parties) is for top management of the new era, as an important part of project management and contract management for consideration in all directions.

\subsection{The theory of the synergy}

Value creation associated or exist various dependencies only seed in the alliance between the multinational corporation, may produce synergy. In a global enterprise system, there are dependencies between most of the enterprises, but not all associated with interdependence formed alliance, produced a synergistic effect. Synergistic effect can appear, is the multinational company according to the associated with dependence on business integration, by integrating and sharing effect. If no connection between two multinational companies to integrate, that their associated is still as before is a loose connection. It is impossible to produce synergistic effect. Integration is not, of course, there is no cost, coordinated higher costs may arise in the process of integration, flexibility and compromise of rigid cost, an evaluative cost performance, etc. The synergy effect reduces the costs of emergence. When the alliance synergy created profits, integration cost has been negative synergies. That is to say, not all together can have a check of the effect of alliance. Part of the coalition did not succeed, may be related to its high cost of integration.

To seek effective management method or management ways and means to shorten the gap becomes primary problem must be solved. Because the management synergy goals and organization system has consistency, as well as the management synergy to the transcendence of the traditional enterprise management, nature of effective management methods to solve the gap. But if we want find the way how to shorten the gap, there are still many things that need to research management implementation process.

\section{Synergy mechanism modes and the multi-sided matching method}

Using the game theory, in the process of selection decisions, project participation main body the parties may agree and accept the new management mode, the synergy management. Main body may also refuse to the new model. Body can continue the original pattern or accept the new model.

\subsection{The Structure to Building the Model}

According to the necessity of management synergy mechanism model to build and train of thought, can build up the management synergy mechanism model, as shown in figure 1: 


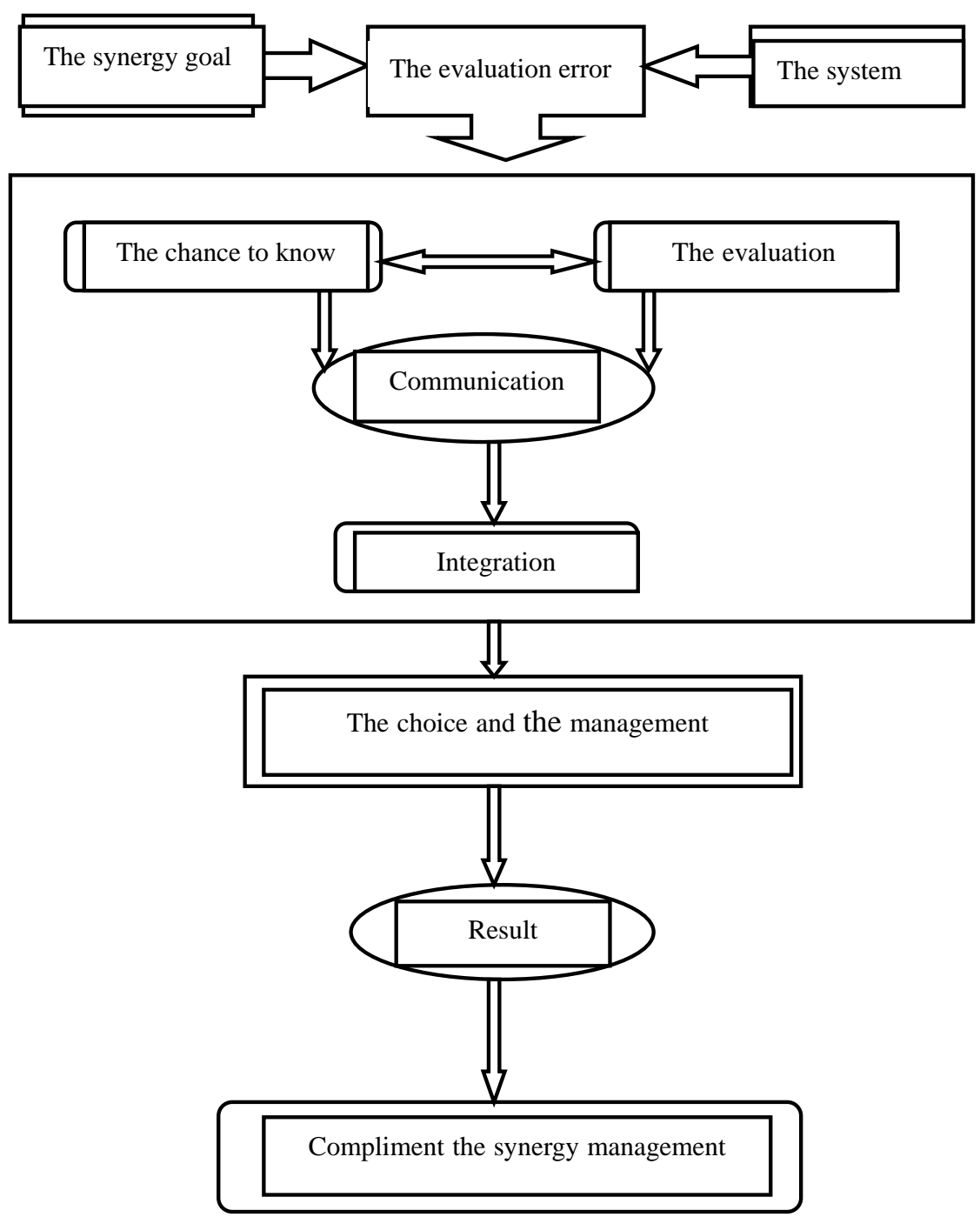

Fig 1: The management synergy mechanism model

According to the building of management synergy mechanism model, can put the management synergy mechanism model of concrete is divided into three major mechanisms, namely the management synergy mechanism (agent), management synergy mechanism (process) and the management of collaborative constraint mechanism.

This part of the said the target of any organization system and management synergy goals consistent on the whole, but the organization system can achieve its goal, still need to analyze its operation condition, find out the organization system development level of reality and the ideal development level (management synergy goals), the gap between recognizing the basis of management synergy and motivation.

\subsection{The Algorithm of the Model}

New model is restricted and influenced by many factors, such as technology development capabilities and risk, market creativity, learning effect, reducing the management risk, manager preferences, and so on. In this paper, the following research is based on the assumption that a principal decisions only two possible to accept and reject. Considering the main body in the market decision-making, the market's guiding roles that are enormous influence and assimilation capacity, and the positive policy in the process of the government is likely to boost. Public opinion model on the basis of the analysis model is established, and mainly analyzes the decisions of managers.

$N_{t}$ is defined as the number of the choice subjects, and

$$
\mathrm{N}=\mathrm{L}+\mathrm{E}
$$

Where, $L_{t}$ is represent as the number of main bodies that accept synergy management; $\mathrm{E}_{\mathrm{t}}$ is the rejected main partner numerical value. Total is set to $2 H(\geq 1)$, and $M_{t}=2 H$, united vertical (1) 
is $D_{t}+F_{t}=2 N$. Suppose a main body can only make a choice, by which building a chosen model $\left\{D_{\mathrm{t}}, F_{t}\right\}$, or said

$$
h_{t}=\frac{L_{t}-E_{t}}{2}
$$

So $\left\{L_{\mathrm{t}}, E_{t}\right\} \rightarrow\left\{L_{\mathrm{t}}+1, E_{t}-1\right\}$ is defined as the equation $h_{t} \rightarrow h_{t}+1$, and $\left\{L_{\mathrm{t}}, E_{t}\right\} \rightarrow\left\{L_{\mathrm{t}}-1, E_{t}+1\right\}$ is defined as the equation $n_{t} \rightarrow n_{t}-1$. In order to make configuration index can continuous, the definitions as following:

$$
x_{t}=\frac{h_{t}}{H}\left(-1 \leq x_{t} \leq 1\right)
$$

Due to the randomness of the choice, so study the probability distribution of the chosen model at time t. Because of the random selection of the choice, we just study the shape $\left\{L_{t}, E_{t}\right\}$ of moment $t$, and then we establish the probability distribution and the postulate, as follows:

$$
\begin{gathered}
G\left(L_{t}, E_{t}\right) \equiv G_{n, t} \\
p_{L \in F}\left[J_{t}, K_{t}\right]=G_{n} \uparrow, \quad p_{F \in D}\left[L_{t}, E_{t}\right]=P_{n} \downarrow
\end{gathered}
$$

In the formula (5), the direction subjects choice to move has been represent as $\uparrow \downarrow$.

And, the probability can be defined as a special formula that is about the choice transition. The special formula of $\left\{n_{D}, n_{F}\right\} \rightarrow\left\{n_{D}+1, n_{F}-1\right\}$ and $\left\{n_{D}, n_{F}\right\} \rightarrow\left\{n_{D}-1, n_{F}+1\right\}$ is

$$
\begin{aligned}
& R_{\mathrm{n}} \uparrow=n_{D} G_{n} \uparrow=(N-n) G_{n} \uparrow \\
& R_{\mathrm{n}} \downarrow=n_{D} G_{n} \downarrow=(N+n) G_{n} \downarrow
\end{aligned}
$$

The distribution shape of the main equation can be defined as follows: $\frac{d G_{n, t}}{d t}=$

$$
\left[R_{n-1} \uparrow G_{n-1}+R_{n+1, t} \downarrow G_{n+1, t}\right]-\left[R_{n} \uparrow G_{n, t}+R_{n} \downarrow G_{n, t}\right]
$$

In order to the subsequent processing become more simple, we make the define as $n=N x$, so we can be obtained for processing to the formula (7):

$$
\begin{aligned}
& \frac{d G_{n, t}}{d t}= \\
& \quad-\frac{\delta}{\delta x}\left[\left(R_{x} \uparrow-R_{x} \downarrow\right) G_{x, t}\right]+\frac{1}{2} \varepsilon \frac{\partial}{\partial x^{2}}\left[\left(R_{x} \uparrow+R_{x} \downarrow\right) G_{x, t}\right]
\end{aligned}
$$

Thinking about the formula (8) and using the Taylor series to process it, then the equations has been given for the public opinion model:

$$
\left.\begin{array}{c}
V x \uparrow=\gamma(1-x) \exp (\theta+l x+\cdots) \\
V x \downarrow=\gamma(1+x) \exp [-(\theta+l x+\cdots)]
\end{array}\right\}
$$

Where, preference is the $\theta$, if $\theta>0$ it means the preference synergy, if $\theta<0$ it says preference for joint; To participate in the main body in a given environment the transfer decision-making for the strength, $\mathrm{l}$ is a subject how to follow change other subject. L is conditioned by many factors, such as the degree of competition, the market changes, increased risk, such as policy changes, the decision-making preferences, turnover and other factors.

Thus, the analysis of the changes on the choice of cooperative management architecture, can clarify the mechanism of synergy management. In today's global economic integration, financial integration, cooperation and communication increasingly frequent, the benefits of that value is bigger, so as to make the focus of the linear stability condition is not reached, bifurcation, and form a new bifurcation point of stability.

Every main body after considering influence factors, tend to accept synergy management the new pattern. In today's world development process of indirect evidence the conclusion of this 
model.

\section{Building the synergy mechanism of project contract management}

Project category gets the further development of economy. This development must go through certain mechanism construction, to realize the goals that are tasks of the participants, resources, information, and the purpose of effective coordination, etc. Synergy management is the process of the preparation together with the actual value of the project, the project process, and its core lies in association rules, form to create, and win-win situation. Synergy management of project contract should absorb the strengths of the synergy theory and theory of contract management system at home and abroad, to explore in a coordinated management mechanism between the main body, strengthen the coordination between the main body of the multi-angle cooperation, improve the main parties benefits together.

\subsection{The multi-sided matching model of synergy subjects.}

In real life, many problems are involved in such a situation, which is a group of subjects need to match with another group of subjects, such as marriage matching problem, buying and selling goods, staff and post matching problem, university enrollment, and so on. Along with the social development, economic management of bilateral matching problem has caused the wider attention of researchers, such as second-hand housing transactions matching problem, venture capitalists and venture enterprises matching problem. Therefore, bilateral matching problem has extensive practical application background.

\subsection{Building organization mechanism using synergy management.}

Social mechanism of cooperative management is through comprehensive economic, legal, policy and other means to the project design and construction for reasonable, moderate adjustment, the elements and the corresponding resource information to synergetic main focus. Implementation projects coordinated management of all participants need to industry leading, society, system and mechanism innovation and guide of the government. Very need government mechanisms play a role here, Blair and Kaserman (1985) has pointed out: "due to the vertical merger of social welfare caused by positive effect is relatively more and widely, the negative effect is relatively small and narrow, thus should be looser regulations about vertical merger control". The government not only lower the transaction cost in society, and develop the principles of fairness and maintenance aspects have the authority. Based on actual, collaborative management is a cross-regional, cross-trade and across a wide range in the field of harmonious and unified scheduling, was the first to establish fair and transparent principles, leading the healthy and sustainable development of cooperative management is very important.

\section{Conclusion}

In this paper, our basic starting point is to maximize project participation main body the interests of all parties. Its aim is to realize the optimization, the choice of conflicts of interest to minimize transaction costs. In this paper, we use synergetic theory to construct a new management model that put forward in there. We use the basic concept of public opinion model, and build a mathematical model for analyzing the mechanism of synergy management, and proof practical application promotion probability and trends. Then, the article established the theoretical model of synergy management mechanism. Through the analysis of the mathematical model demonstrates, the project main bodies in the consideration of many factors are more likely choose cooperative organization, and the analysis of the preference transfer was beneficial to the improvement of the efficiency of cooperative management and performance. On the basis of the theoretical model of synergy management, we try to build a more accurate and practical application model. 


\section{References}

[1] Jonathan Grudin.Computer-supported cooperative work: history and focus[J].IEEE Computer, 1994, 27(5):19-26.

[2] H. Haken. Advanced Synergetics: Instability Hierarchies of Self-Organizing Systems and Devices [M]. Springer-Verlag, 1983.

[3] Veronica Se ano,Thomas Fischer.Synergy innovation in ubiquitous systems [J].International manufacturing, 2007 (18) : 599-615.

[4] Karl Marx. Capital [M], World Publishing Corporation, 2011.

[5] Adam Smith. The Wealth of Nations [M], Create Space, 2010: 56-57.

[7] Xiaokai Yang. Principles of Economics [M]. Beijing: China Social Sciences Press,1998:78 -80

[8] Yongkun Ma. Synergy innovation theory model and the construction of regional economic cooperation mechanism [J]. East China Economic Management,2013,20(02):52-55. 